April - 2003

\title{
Challenges for Study Centers in an Electronic Age: A case study of the Center for Distance Education at Carl von Ossietzky University of Oldenburg in Germany
}

\author{
Ulrich Bernath, Axel Kleinschmidt, Christine Walti, \\ Olaf Zawacki \\ Carl von Ossietzky University of Oldenburg \\ Germany
}

\begin{abstract}
This paper reports on developments in study centers in Germany and in particular the experience of the Center for Distance Education at Carl von Ossietzky University of Oldenburg. Emphasis in this paper has been placed on the challenges faced by German universities in the electronic age, which in its early stages began in 1995. The purpose of this paper is to ground the establishment of open and distance study centres vis-à-vis the unique cultural and institutional circumstances characteristic of Germany and its institutions of higher education.
\end{abstract}

\section{Development of Distance Education in Germany}

This paper reports on developments in study centers in Germany and in particular the experience of the Center for Distance Education at Carl von Ossietzky University of Oldenburg, with emphasis on the challenges faced in the electronic age - which in its early stages began for us in 1995. Our practice necessarily refers to specific cultural and institutional circumstances characteristic of Germany and its institutions of higher education ( Kappel, Lehmann, and Loeper, 2002).

Distance education at the university level in Germany has, for many years, been the province of the FernUniversität in Hagen, a specialized distance teaching university founded in 1975. The FernUniversität became a large scale provider of courses in economics and business administration, social sciences, humanities, law, computer science, and electrical engineering taught at a distance. Today, the FernUniversität offers a total of about 1,500 courses to more than 59,000 students. Each course varies from 20 to 180 learning hours, which are completed within a semester measuring 15 weeks long. The majority of students - around 85 percent in the year 2001 - were degree-seeking (FernUniversität, 2001). The system is open to students who enroll in individual courses for continuing education; although they cannot earn a degree, they study under the same conditions as degree-seeking students. 
Bernath, Kleinschmidt, Walti, Zawacki \& Von Ossietzky

Challenges for Study Centers in an Electronic Age

The FernUniversität does not follow the Open University UK (OU UK) model of decentralized student support, with study centers scattered nationwide, and tutors as core staff members for all enrolled students (Groten, 1992; Tait, 2002). Instead, as a state run university of North-Rhine Westfalia, the FernUniversität may only operate within the borders of North-Rhine Westfalia. To provide equal opportunities for the more than 60 percent of their students living in other German states, regional student support services are provided in fifteen other German states.

In 1978, the respective ministry in the state of Lower Saxony institutionalized its own statewide support system for its students attending the FernUniversität, establishing central academic units for distance education within three conventional universities in the cities of Hildesheim, Lüneburg, and Oldenburg. These partner institutions became responsible for providing support to the students of the FernUniversität as a regional study center, and for developing and delivering their own distance teaching programs in cooperation with the faculty of the respective home universities.

Thus, with establishment of its Center for Distance Education, Carl von Ossietzky University of Oldenburg found itself responsible not only for serving its own university faculty and students in the area of distance education, but also students of other distance teaching universities (mainly those of the FernUniversität). This multifunctional structure of central university units for distance education in Lower Saxony represents a "special case" (Wissenschaftsrat, 1992, p. 36) in German higher distance education. This concept was unusual even by international standards, representing a new challenge for conventional universities within their centers for distance education (i.e., Mills' taxonomy of study centers, 1996).

In order to provide stronger regional distance education delivery centers, in 1992 the Wissenschaftsrat (German Science Council, http://www.wissenschaftsrat.de/) proposed the establishment of centers for distance education in various universities. In addition, the German Science Council recommended establishment of cooperative models between central distance teaching institutions and local/ regional universities. Endorsing the visionary policies adopted in the 1970s by the German states of Lower Saxony, Bremen, and Hesse, in 1993 the same council promoted formation of a national network of distance learning centers at both university sites and elsewhere (Wissenschaftsrat, 1992; 1993). In 1995, eleven representatives from centers for distance education as well as from centers for distance and continuing education at the universities in Berlin, Frankfurt, Hamburg, Hildesheim, Kaiserslautern, Karlsruhe, KoblenzLandau, Lüneburg, Oldenburg, and Saarbrücken, founded the Arbeitsgemeinschaft für das Fernstudium an Hochschulen (AG-F), or in English, the German university association for distance education and open learning. To date the AG-F has attracted more than 50 member institutions that collectively offer a wide range of open and distance learning programs for more than 10,000 undergraduate students, as well as an array of non-degree programs for continuing education and professional development (http://www.ag-fernstudium.de).

This multifunctional orientation to distance education and open learning, declared almost 25 years ago as the mission of the three Lower Saxony centers for distance education, appears to have resulted in central units for distance education at conventional universities that meet all of the fundamental functions of study centers mentioned by Mills (1996). Services for advising and supporting students in general, and providing tutorials for students of the FernUniversität in particular, have gained a reputation for high quality as evidenced in projects, experiments, and evaluations. With respect to the Oldenburg Center for Distance Education, development of its own and joint programs, mainly in continuing education and professional development, has been remarkably successful and sustainable (Bernath, 1993; 1994a; 1994b; 1996; 2001; Bernath and 
Bernath, Kleinschmidt, Walti, Zawacki \& Von Ossietzky

Challenges for Study Centers in an Electronic Age

Rubin, 2001). Continuing education programs for professionals in healthcare delivery (http://www.gesundheitspartnerschaft.de/), teacher training programs in economic education (Feeken, Kleinschmidt and Zawacki, 2002), and the Master of Distance Education program, a joint venture with the University of Maryland University College (Bernath and Rubin, 2002) are just some examples of developmental accomplishment.

\section{Organizational Aspects of the Center for Distance Education in Oldenburg}

Within the framework of agreements on cooperation between the two universities, the Center for Distance Education at the University of Oldenburg is autonomously responsible for providing student support services for students of the FernUniversität. However, counseling and tutoring are more aligned within the concepts and organizational structures for student support services provided by regional offices of the OU UK, than that of the FernUniversität's study centers in North-Rhine Westphalia (Bernath, 1992).

By 2002, the Center for Distance Education at Oldenburg University had established more than 50 positions on three levels of operation:

- Six academic area managers and program coordinators

- Approximately 50 part time mentors/ tutors and temporary project employees

- Five part time administrative positions to manage - i.e., more than 3,000 tutorial hours for students of the FernUniversität, contract faculty, teachers, moderators, and facilitators for the various programs oversee the budget and to run the everyday administration of the center.

Related to mentoring/ tutoring and advising, one of the main responsibilities of academic area managers and program coordinators is to recruit part time mentors and direct them in their subject areas. They may also advise and mentor distance students themselves and participate in the development of programs and projects within the university. The main difference between the German and the OU UK distance education systems is that in Germany tutors do not participate in course development and student assessment, and for this reason tutors are called "mentors." Nevertheless, these positions require participation in the development and management of distance teaching and open learning programs within the home university. This means academic area managers and program coordinators in the Center for Distance Education must develop appropriate responses to the:

- Changing roles of the mentors, tutors, and teachers

- Increasing number of students who expect instruction outside ordinary classes and schedules

- Growing importance of new communication and information technologies

- Development of new programs and the redesign of curricula

- New networks for delivery and communication

- Further development of adequate student support services (Bernath, 1996)

Tutorials for Students of the FernUniversität provided by Mentors at the Center for Distance Education at Oldenburg University 
Bernath, Kleinschmidt, Walti, Zawacki \& Von Ossietzky

Challenges for Study Centers in an Electronic Age

Until 1995, mentors supported their students exclusively in face-to-face meetings at study centers. Professional support provided by the mentors goes beyond answering of questions about the subject matter and content. Mentors set course-related focuses, describe relationships from their particular point of view, reveal common themes in the materials, initiate discussions, and give additional examples (i.e., The roles of the tutor in Thorpe, 1992). Characteristic of the mentor's role is the formation of special bonds of trust between mentors and students, which is facilitated by the fact that mentors do not assess their students. Perhaps even more important is the opportunity for students to meet in groups, which encourages the exchange of ideas and learning experiences.

Mentors offer face-to-face meetings in Oldenburg through a mix of evening, Saturday, and weekend classes, as well as weekly residential schools. This mix is the result of various factors, such as the specific requirements of the subject areas, students' needs, availability of resources, and the overall features of the study center's program for face-to-face meetings. Few other study centers connected to the FernUniversität offer such combinations of face-to-face events.

Evening classes attract students living within the vicinity of a study center, and are regular events that follow the pace of the courses. Empirical evidence shows that 30 minutes of travel time to the meeting point with the mentor is the upper limit for the vast majority of students living in the North Western German region (Bernath and Hohlfeld, 1993). Day schools and, even more so, residential schools conducted over a weekend or an entire week, attract students from further a field and thus distance is perceived to be less of a problem. However, residential schools are singular events, a limited resource, and are not suited to accompany self-directed study. Due to the limited resources available at each of the Lower Saxony Centers for Distance Education in Hildesheim, Lüneburg, and Oldenburg, a satisfactory mix of opportunities could not be provided by one study center alone. But by cooperating together, these centers have been able to pool resources and capacity to make coordinated weekend and educational leave events available to students.

This mix of events delivered in face-to-face meetings between mentors and students, offers those studying at a distance an opportunity to make choices in terms of their participation. These various events are intended to allow as many students as possible to take part in meetings with mentors, especially prior to assignments and examinations.

Results from a 1997 survey based on a questionnaire distributed to 292 students, showed a high level of satisfaction in terms of the student support services offered by the Center for Distance Education (Mean=3.34 on a 4-level scale). The success of tutorials in weekend-seminars at residential schools was particularly marked (Mesenholl, 1998), suggesting the stabilizing effects on students of student support services.

In the mid 1990s, when the Internet became more ubiquitous in students' homes, the FernUniversität was suddenly confronted with radical questions regarding face-to-face tutorial components. We realized that mentoring students through the Internet would help overcome existing and limiting factors inherent in face-to-face meetings, specifically the geographical distance between students and the study center, and the distance in time between the process of self study and fixed and paced tutorial event. New possibilities emerged with the Internet students could now overcome geographical distances, while at the same time stay current with paced courses. 
Bernath, Kleinschmidt, Walti, Zawacki \& Von Ossietzky

Challenges for Study Centers in an Electronic Age

Figure 1. The Impact of Distance in Space and Time in Various Tutorial Events

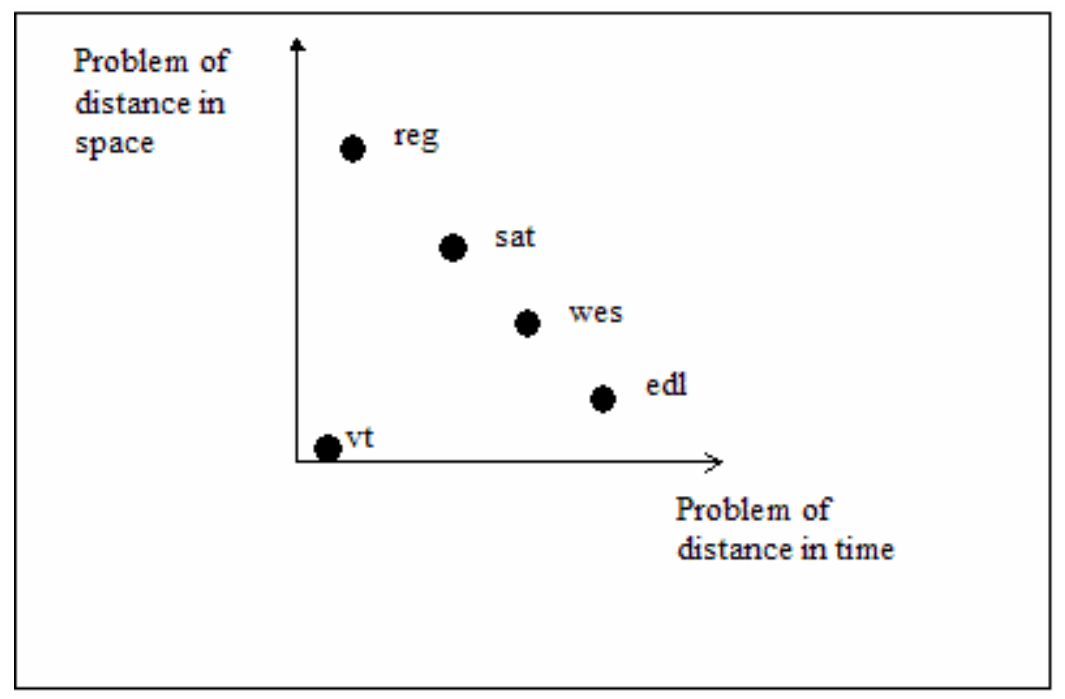

(Legend: reg = evening class; sat $=$ day school on Saturdays; Wes = residential school at weekends; edl = educational leave during a week in residential schools; vt = virtual tutoring/ online tutorials)

With the goal of improving tutorial services, in 1996 mentors offered their services via the Internet for the first time. Experiments with virtual tutorials in mathematics, business administration and economics, macroeconomics, psychology, and quantitative methods in social sciences took place. These experiments led to a change in emphasis in the mix of offered events.

\section{New Perspectives with Online Tutorials}

At that time we could foresee that this new form would require several changes, and hence, a reallocation of limited resources was necessary. We recognized that online tutorials were structurally different from face-to-face tutorials. By introducing online tutorials that were structurally different, but at the same time complementary to face-to-face tutorials, we ran into a "juggling game." We discovered that online tutorials and face-to-face tutorials at residential schools matched perfectly, and thus they became the major "playing balls" in our juggling game. New organizational measures were undertaken to integrate online tutorials into an already established mix of face-to-face tutorials.

Experienced in conducting face-to-face meetings with students, mentors were considered to be the backbone of such a strategy. Mentors were regarded as privileged content experts, while at the same time they were expected to apply the new media and to facilitate different interaction and communication processes when conducting virtual tutorials. In a change process with such high expectations, mentors clearly needed support and professional development in order to increase their skills and to make full use of the new media's potential. Furthermore, the complexity of the change process required formative evaluation to allow reflection and revision for further development. 
Bernath, Kleinschmidt, Walti, Zawacki \& Von Ossietzky

Challenges for Study Centers in an Electronic Age

Figure 2. The "Juggling Game” with various tutorial events
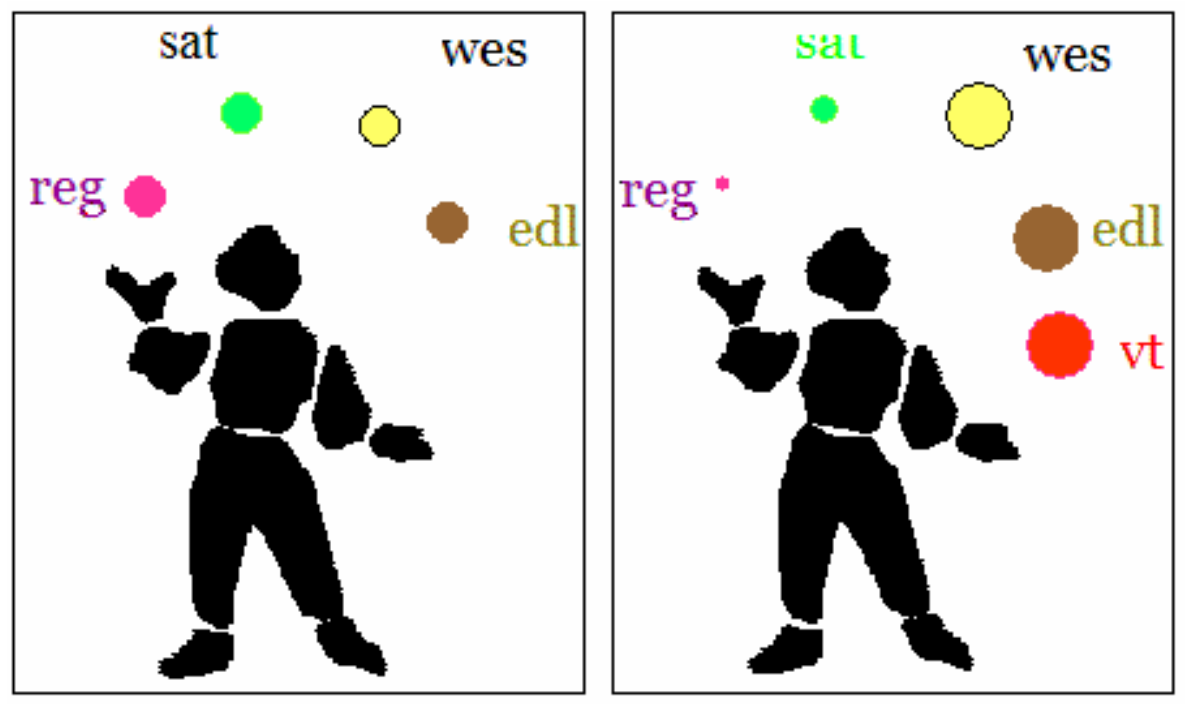

(Legend: reg $=$ evening class; sat $=$ day school on Saturdays; Wes $=$ residential school at weekends; edl = educational leave during a week in residential schools; vt = virtual tutoring/ online tutorials).

In order to go beyond the traditional scope of face-to-face-tutorials, apply virtual tutoring and steer the change process successfully, we became aware that significant investments would be required in infrastructure and personnel, as well as leadership and management. Based on these perspectives about the new online component in the mix of tutorials, we decided on our first conceptual and strategic criteria:

- Low cost and easy access for students

- Preferably asynchronous communication

- Password protection for study groups/ platform neutral

- $\quad$ Service to all academic disciplines

- Combination of online and face-to-face tutorials

- Reallocation of resources for online tutorials

- Increased division of labor (managing a more complex system)

- Promotion of new models of cooperation

- Urgent need for professional training

\section{Preliminary Findings with Online Tutorials}

One of the most important findings was that online tutorials could not - as far as we could see substitute for all face-to-face tutorials. Online tutorials compete first of all with evening classes. However, with integration of online tutorials the attractiveness to students of compact weekend residential schools and weekend seminars has increased. We also became aware that new pedagogical considerations needed to be taken into account.

We learned that restructuring and redesigning the format of tutorials requires collaboration and that the complexity of managing online tutorials required large-scale organization. A 
Bernath, Kleinschmidt, Walti, Zawacki \& Von Ossietzky

Challenges for Study Centers in an Electronic Age

collaborative approach to sustain investments in a technical platform and a program of online tutorials was required. Fortunately, the Lower Saxony central university units in Lüneburg, Hildesheim, and Oldenburg, were able to build on their already existing collaborative efforts, and a new dimension of shared ownership for the online learning environment emerged to fill this need.

With a common teaching platform, the networked design of tutorials had to be reconsidered in order to integrate online tutorials into the existing mix. As analyzed and phrased by Thorpe (2001, p.16), the approach to this new practice can be characterized as "CMC-added-on." Under these circumstances, serious constraints had to be tackled. Because the majority of mentors are employed on a part time basis, they had limited availability for extensive and experimental online commitments, just as their availability for weekend and even weekly residential schools had also been limited. Likewise, just as inter-institutional cooperation had been crucial for the establishment of a network of mentors in cooperating university centers for distance education for compacted face-to-face tutorials, it was also essential for new online tutorials. The emerging online format forced us to increase and further develop the levels of collaboration in two directions. First was the establishment of the technical infrastructure, and second was a joint effort to provide online mentoring through the compilation of sparse resources from collaborating centers. In the first case, a new type of inter-institutional ownership came into place. In the second case, a new model of virtual study center emerged.

Strategic planning incorporated first-hand experiences from our online experiments in virtual tutoring and from the virtual seminar for professional development in distance education (Bernath, 1997; Bernath, U. and Kleinschmidt, A., 1998; Bernath, U. and Rubin, E., 1998; 1999a; 1999b). We found that the pattern of activity among participants engaged in online tutorials was markedly different from the well-known patterns found in face-to-face events. In an asynchronous online environment, many more participants could raise their issues at the same time and they felt less inhibited to raise questions and post half-finished thoughts. This caused a significant increase of visible activities, which forced us to think about the "critical mass" of participants, as well as the flow of information. As a general rule, we consider 15 to be the minimum and 25 to be the maximum number of participants to optimally conduct a conversational approach and active dialogue model in online tutorials. This compares to other findings about class and community sizes in online learning (Boettcher, 1999; Allen, 2001; Rovai, 2002).

The sheer volume of online activity could be overwhelming for both the tutor and the student. There was no doubt that the workload for online tutors would be significantly higher than in faceto-face teaching, as has often been reported (Goodfellow, 1999; Daniel, 2000; Bernath and Rubin, 2001).

We favored the asynchronous mode of computer conferencing. Our experience showed that the asynchronous mode allows students to think over the postings for a while, re-think them later, or even sleep over a message before responding. It seemed to be much like throwing a stone into the water (the incoming message) and seeing the ripples expanding outward (the pondering on the content of the message). Spontaneity in asynchronous communication is no doubt lost, but one "works" on the answer to be given. Such pondering allows students to go in-depth, a process which enables new ideas and notions to surface. Furthermore, written contributions to the discussion remain, which thus has an affect on later discussions. With the "ripple effect" in asynchronous dialogues, as Bernath (Bernath and Rubin 1999a) coined it, we gain the power of reflection, which may substitute for the lack of spontaneity. 
Bernath, Kleinschmidt, Walti, Zawacki \& Von Ossietzky

Challenges for Study Centers in an Electronic Age

While online teaching and learning was becoming an increasingly important issue, an urgent need for new classroom settings that supported the development of computer-based collaborative learning in face-to-face events arose at the same time. In 1997/ 98, the Center for Distance Education became a partner in a joint venture, whose goal was to design a physical setting that enhanced computer-supported collaborative learning. A round table with six networked computers and fold-away monitors was developed as a base model that allowed up to 18 (and in its advanced version with eight workstations up to 24) participants to meet in a seminar room setting rather than a computer lab. This model combines computer supported group interaction with traditional face-to-face meetings. It also allows the combination of both "real" and "virtual" learning spaces. This new seminar setting (see http://www.uni-oldenburg.de/zef/silva/index-e.htm and http://www.uni-oldenburg.de/zef/cebit/ceho-ine.htm) has made possible radical changes in the pedagogy of tutorials and seminars. The availability of a learner-friendly physical environment in combination with a new online learning infrastructure, retains the commitment to the idea that "the student comes first" in face- to-face as well as in online learning.

\section{New Pedagogical Concepts}

Because online tutorials represented a new approach, we did not discover its full potential immediately. Indeed, we were too attached to the notion of the traditional face-to-face paradigm of tutorials to see the full potential of the new online media. Distance teaching universities and study centers faced new pedagogical questions and organizational changes. In 1997, the key points of a new pedagogical concept were formulated for online tutorials (Bernath and Kleinschmidt, 1998):

- Mentoring services via the Internet should not be limited to solely answering questions. Mentors must work to stimulate and structure discussions through the use of both continuous and strategically placed course subject content. Such tactics are particularly important if the course is not paced by deadlines primarily because participants are unlikely to be working on the same topics at the same time. What these inputs should consist of depends greatly on the subject and the topical emphasis of the mentors.

- Communication should be asynchronous, structured, and paced to support study groups and learning in a community.

- Online mentors should also be experienced in the face-to-face tutoring environment, which has provided an indispensable input to increase the quality of online mentoring and vice versa.

- Social relationships and emotional aspects play an important role for learning behaviors in the online environment. Measures should be undertaken give participants the opportunity to form groups and to contact each other directly and individually.

- In the online environment, group size must be limited. To deal with the volume of interaction between mentors and participants and for group members still identify themselves as such, it may be necessary to divide the group, especially if its size goes beyond a specified number. 
Bernath, Kleinschmidt, Walti, Zawacki \& Von Ossietzky

Challenges for Study Centers in an Electronic Age

- Activities of participants engaged in an online seminar is different than those engaged in a face-to-face event. In a virtual seminar false impressions can arise that only a small part of the group is active. However, the reality may be that others are working actively, but simply do not see the need to make a contribution. This misperception can be mitigated through appropriate group moderation. Answering an individual learner's contribution can be made comprehensible to all by preparing a newsgroup and thus creating the impression of "one-to-many" communication.

- The high workload typical of initiating online tutorials - in particular for mentors/ tutors - can gradually be decreased by re-using generic contributions. However, such tactic requires certain technical conditions and faculty support services, both of which must be created and sustained.

\section{Strategic Concepts}

At the center of our strategy to sustain online tutorials and their economic operation, stands the reality that the effective operation of a well functioning online tutoring system cannot be lead by a single center for distance education or institution. This reality has led us to seek increased cooperation with several institutions so as to pool resources and to focus on the following areas:

- Selection and operation of a joint technical infrastructure: In the first few semesters, classical Internet tools (www, news groups, E-mail, FTP) were used. Existing restrictions, especially in terms students' ability to generate interactive options such as, for example, the creation of graphs with formulas, made formulation of alternative procedures necessary.

- Necessity to regulate labor legislation: Mentors should be able to provide online tutorials from their homes and independent of fixed times. New procedures for compensation and cost reimbursement were needed.

- Training and counseling of mentors: The training and counseling of mentors not only technically, but also didactically - became a complex task, for which individual and group measures for professional development needed to be linked. Concerns about cost-effectiveness of group tutoring versus training of individuals also needed to be resolved.

- Technical introduction and counseling for Learners: Learners also require an introduction to technology, and hence technical questions must be addressed from the outset.

- Joint support of courses: A team-teaching approach was used to lessen each mentor's workload, shorten response time to learners, and to obtain its didactical advantages.

- Evaluation: Formative evaluation should support the development of online tutorials and strengthen quality management. 
Bernath, Kleinschmidt, Walti, Zawacki \& Von Ossietzky

Challenges for Study Centers in an Electronic Age

\section{Online Tutorials through 'Virtual Study Centers'}

In 1999, after thorough consideration of various alternatives, Lotus Learning Space was chosen as the learning platform and online learning management system. The State of Lower Saxony made the technical infrastructure possible within the framework of a grant project (Virtual learning spaces in higher education: http://wwwfz.uni-luene-burg.de/FERN/3-STUPRO/Projekte/viles.htm) with the expressly stated goal of making it available for other online learning offerings at Lower Saxony universities.

In 2002, distance learners could enroll in 19 online courses from the various subject areas. Each year between 350 and 400 students make use of this service. Students purchase a license for the software (Lotus Notes Client and Lotus Smart Suite) and are provided a CD on which, besides the programs, are pre-prepared contributions by their mentors. Students install the software at home. Configurations are performed automatically and students only need to choose their courses, students then briefly log-on to the Internet to download any updates or newer versions. Because only new or changed documents are transmitted online, the time necessary for such housekeeping is minimal. Students then proceed to learn their course material off-line without a connection to the Internet. When they have completed an assignment, they upload their assignments and contributions, thus making their work available to others. With appropriate software, students may also copy or work with formulas, graphs, or work sheets provided by mentors. If a server fails, students are automatically switched to another server. Participants rarely encounter a down server. Students who do not wish to install the software may participate via a www browser, but they must be online to do so. However, their online participation is limited strictly to newsgroups. Access to contributions made by mentors and other students is possible without any restrictions. Because students use a seamless system, they do not need to be aware of the complex structure that supports their learning environment.

Figure 3. Technical infrastructure of the "Virtual Study Center"

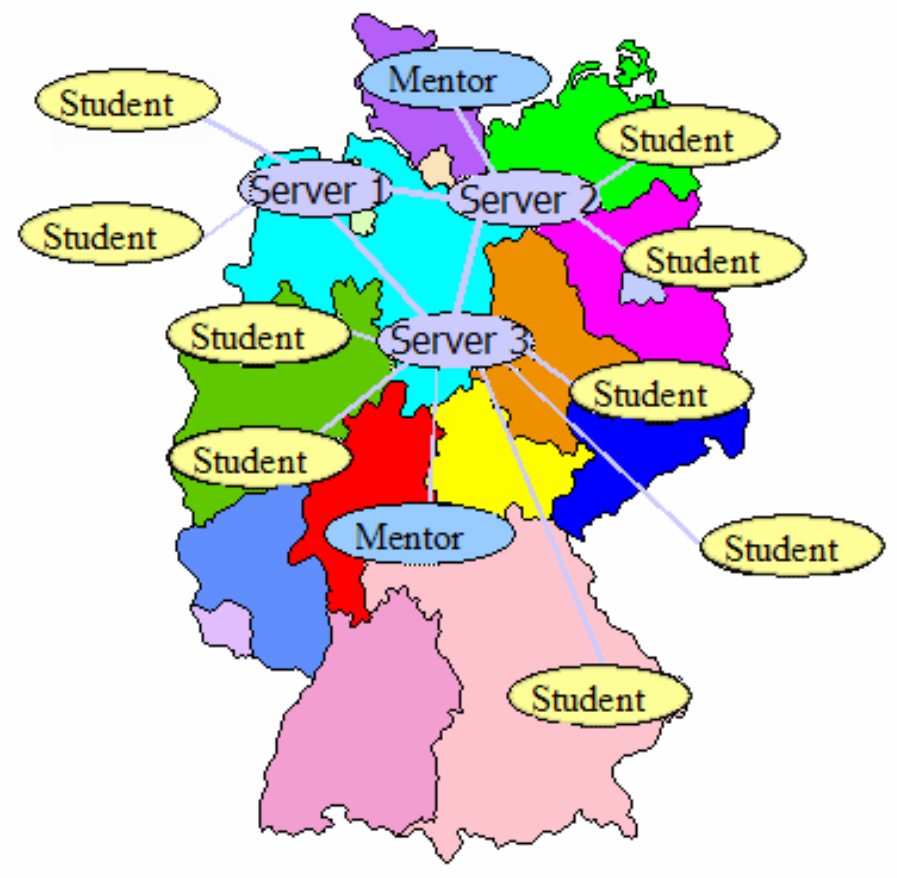


Bernath, Kleinschmidt, Walti, Zawacki \& Von Ossietzky

Challenges for Study Centers in an Electronic Age

Nine servers hosting online learning software (i.e., Lotus LearningSpace) and three backup servers at the universities in Hildesheim, Lüneburg, and Oldenburg form the technical backbone of this interactive online delivery system. In order for courses and materials to remain current, servers must be updated regularly. Mentors and students only need a short time to connect to the servers for downloading purposes. The twenty-one mentors who serve the student population live in different locations and are employed at the various universities' study centers. For courses, mentors from different centers jointly support a given course. For students, however, local connections and references to their study center have become blurred; they use the coordinated, networked online tutorials and student support system as an offering from a single virtual distance learning center.

With regards to the changing role of local and regional study centers, similar developments have been described by Tait (2002). A joint staff development project with tutors from the OU UK regional office in Cambridge also shows similarities, but also differences in comparisons across boarders and institutions (Gaskell and Mill, 2002).

\section{Challenges and Outlooks}

One of the major challenges was - not surprisingly - the qualification of the mentors necessary for online student support. The importance of professional development for mentors or "emoderators" should not be underestimated. Our experience stands in close concordance to Salmon who said: "Any significant initiative aimed at changing teaching methods or the introduction of technology into teaching and learning should include effective e-moderator support and training, otherwise its outcomes are likely to be meager and unsuccessful” (2000, p. 55). Therefore, a training program with introductory and developmental elements was designed; it was both well received and sufficient, which enabled mentors to become comfortable with system. In terms of technical skills, however, mentors were found to be heterogeneous, especially with regard to their course specific needs. This reality led to high demand for individual support during the training period, which could only be met in personal discussions. In the future, qualitative aspects of such training will have priority over quantitative development in order to enable mentors to fully utilize the system's features and thus increase student success. This is especially true in Oldenburg, where the number of online tutorials has increased dramatically and hence, can no longer be viewed as a mere addition to face-to-face events. Online tutorials over the Internet have developed their own dynamics.

There was a strong expectation of re-using once compiled content and thus lowering the amount of required work for tutorials. Like building a house, developing and delivering a course involves an extraordinary effort in the beginning, after which a databank can be developed that over time can continuously be expanded and improved with new information. In some cases, the workload can be reduced, while in other cases, especially where the content must be continuously updated or revised, the workload is significantly heavier. Because the online learning environment favors the reuse and redesign of content and continuous updates, the workload usually remains higher than expected.

The experiences of all mentors are the subject of evaluation and exchanges. In Fall 2000, followup telephone interviews showed that for most mentors the online environment involved additional and unexpected efforts. The adaptation was more of a challenge than expected. Although this finding was troublesome, the mentors appreciated the support and training they received, and eventually all but one mastered the new teaching situation. A small group of mentors reported 
Bernath, Kleinschmidt, Walti, Zawacki \& Von Ossietzky

Challenges for Study Centers in an Electronic Age

that they had no problems in the new environment and mastered it easily. Because all mentors had previously taught in face-to-face settings, they experienced and appreciated the advantages of the online environment. Nonetheless, they still complained about the lack of visible participation and feedback in groups of 8 to 15 participants.

A survey showed that most students enrolled in the online and face-to-face study modes, viewed the online tutorials as an important supplement. Only a few students mentioned encountering technical problems.

Participating institutions discovered that the complex nature of cross border cooperative relationships relied upon the successful operation virtual distance study centers. With respect to the basic conditions, it was difficult to align education policies and developmental politics at each institution that still revolve around issues of physical area and space. Conventional territorial structures continue to be in opposition to the non-spatial world of this new and worthwhile process of teaching and learning via the Internet. Viewed in this manner, it is not so much a matter of putting a "new ball" into play and adjusting weights (See Figure 2, The "juggling game"), but about introducing profound qualitative changes in the educational field and the organizations involved in such an endeavor.

New and promising developments are on the horizon for distance learning and training. Time and space are already loosing their constraining effects. Online tutorials have already proven their worth in terms of facilitating highly effective interaction and communication between mentors and students engaged in distanced education studies. Daily, we are faced with challenges to find new ways and means along a technological continuum of more or less complex solutions, in what is proving to be a never-ending process of development. However, technology is not selfsupporting and content is not self-explanatory. Nor is technology the new teacher - teachers and mentors remains the focus of all teaching and learning. However, teachers and mentors require new skills to be effective online educators (Salmon, 2000). Providing access to technology through study centers is necessary, but not enough. Online learning only works well when it creates enthusiasm. Students, teachers, and mentors alike must be comfortable with the technology before they can successfully master online learning. However, when taking into account that online learning participants are "technologically favored" in that they possess access to technology and the requisite skills to participate, it is clear that online distance education delivery may systematically disadvantage those who lack the tools and skills, and will likely not participate without help and encouragement. This issue not only a local matter, but rather a global one which is now becoming evident as the gap between the information-rich and the informationpoor grows. Unfortunately, the digital divide is a significant problem for which we still lack the appropriate answers.

\section{References}

Allen, N. H. (2001). Lessons learned on the road to the virtual university. Continuing Higher Education Review 65, 60 -73.

Bernath, U. (1992). Zur Stellung und zum Stellenwert der Mentorentätigkeit im Fernstudiensystem der FernUniversität Hagen. Ein Diskussionsbeitrag aus dem (nichtnordrhein-westfälischen) Fernstudienzentrum der Carl von Ossietzky Universität Oldenburg im Jahre 1991. In N. Bückmann, G. E. Ortner und R. Schuemer (Eds.) Lehre und Betreuung im Fernstudium, Abschlußbericht zum Ringkolloquium des Zentralen 
Bernath, Kleinschmidt, Walti, Zawacki \& Von Ossietzky

Challenges for Study Centers in an Electronic Age

Instituts für Fernstudienforschung (ZIFF) der FernUniversität im Wintersemester 91/92, 75-87. Hagen, Germany: FernUniversität - Gesamthochschule. Retrieved June 18, 2002 from: http://www.uni-oldenburg.de/zef/literat/mentoren.htm

Bernath, U. and Hohlfeld, G. (1993). Zur Abgrenzung des Einzugsbereiches eines Fernstudienzentrums in: 15 Jahre Beratung und Betreuung für Studieninteressenten und Studierende der FernUniversität - Gesamthochschule - Hagen durch das Fernstudienzentrum der Carl von Ossietzky Universität Oldenburg 1978 - 1993, Oldenburg: BIS-Verlag.

Bernath, U. (1993). Summarizing remarks on 15 Years of the Center for Distance Education at Carl von Ossietzky University of Oldenburg. Retrieved June 18, 2002 from: http://www.uni-oldenburg.de/zef/literat/15jeng.htm

Bernath, U. (1994a). The Center for Distance Education at Carl von Ossietzky University of Oldenburg. Open Learning 9(3), 52 - 55. Retrieved June 18, 2002 from: http://www.unioldenburg.de/zef/literat/centrwww.htm

Bernath, U. (1994b). Proposal for multifunctional resource and developing centers at conventional universities to promote higher distance teaching and open learning in the European Open University Network. In F. Palank and N. Pronk (Eds.), EuroStudyCentres. Beiträge zur Entstehung des European Open University Network. Zeitschrift für Hochschuldidaktik, 18(1), 93 - 103. Innsbruck: Österreichischer Studienverlag. Retrieved June 18, 2002 from: http://www.unioldenburg.de/zef/literat/proposal.htm

Bernath, U. (1996). Distance education in mainstream higher education: A strategic issue at conventional universities. In M. Thompson (Ed.), Internationalism in distance education: A vision for higher education. Selected papers from the first International Distance Education Conference, Pennsylvania State University (p. 45-51). University Park, PA.: American Center for the Study of Distance Education, The Pennsylvania State University. Retrieved June 18, 2002 from: http://www.unioldenburg.de/zef/literat/mainwww.htm

Bernath, U. (1997). Virtual Tutoring: A new approach challenging future developments in distance education. Paper presented to the International Conference for Managers of EuroStudyCentres, ESC 97, Helsinki, November 23. Retrieved June 18, 2002 from: http://www.uni-oldenburg.de/zef/literat/virttut.htm

Bernath, U., and Kleinschmidt, A. (1998). Mentorielle Betreuung im Internet - Eine Herausforderung für die Weiterentwicklung des Fernstudiums. Manuskript, Oldenburg, Germany: Center for Distance Education, Carl von Ossietzky University of Oldenburg. Retrieved June 18, 2002 from: http://www.uni-oldenburg.de/zef/literat/intbetr.htm

Bernath, U., and Rubin, E. (1998). A virtual seminar for international professional development in distance education. Informatik Forum 12(1), 18 - 23. Retrieved June 18, 2002 from: http://www.uni-oldenburg.de/zef/literat/forum.htm 
Bernath, Kleinschmidt, Walti, Zawacki \& Von Ossietzky

Challenges for Study Centers in an Electronic Age

Bernath, U., and Rubin, E. (1999a). An international virtual seminar for university faculty and administrators: Professional development in distance education. Paper presented to the 19th ICDE World Conference in Vienna, June 23, 1999. Retrieved June 18, 2002 from: http://www.uni-oldenburg.de/zef/literat/vienna2.htm

Bernath, U., and Rubin, E. (1999b). Final report and documentation of the virtual seminar for professional development in distance education. Oldenburg, Germany: BIS-Verlag. Retrieved June 18, 2002 from: http://www.uni-oldenburg.de/zef/literat/docum.htm

Bernath, U., and Rubin, E. (2001). Professional development in distance education - A successful experiment and future directions. In Lockwood F. and A. Gooley (Eds.) Innovations in open and distance learning, successful development of online and web-based learning. London: Kogan Page. Retrieved June 18, 2002 from: http://www.unioldenburg.de/zef/literat/uligene.htm

Bernath, U. (2001). From distance education to online teaching and learning. In Projektstudium Fernstudium - Online-Studium; Beiträge zur Weiterentwicklung von Studium und Lehre. Dissertation. Oldenburg, Germany: Fachbereich 1(Pädagogik), Carl von Ossietzky University. Retrieved June 18, 2002 from: http://www.uni-oldenburg.de/zef/literat/dissall.pdf

Bernath, U., and Rubin, E. (2002, forthcoming). Reflections on teaching and learning in an online master program. Oldenburg: BIS-Verlag.

Boettcher, J. V. (1999). How many students are just right in a web course? Retrieved October 30, 2001 from: http://www.cren.net/ jboettch/number.htm

Daniel, J. (2000). The future of online learning. Executive Briefing at Toronto, November, 15. Retrieved June 23, 2002 from: http://www.open.ac.uk/vcs-speeches/Toronto.htm

Feeken, H., Kleinschmidt, A. and Zawacki, O. (2002). Das Konzept der Online-Betreuung im Projekt "Ökonomische Bildung online". Paper to be presented at the GMW-Jahrestagung 2002, Sep 17 - 19, 2002 University of Basel, Switzerland.

FernUniversität (2001). Studierendenstatistik. Ausgewählte Daten zur Struktur der Studierenden. Wintersemester 2001/2002. Dezernat 2.3. Hochschulplanung - Akademische Angelegenheiten. Hagen, Germany: FernUniversität - Gesamthochschule.

Gaskell, A., and Mills, R. (2002). Collaboration in training and staff development across institutional and national boundaries. In Szücs A. and E. Wagner (Eds.) Open and Distance Learning in Europe and Beyond. Rethinking international co-operation. Proceedings of the 2002 EDEN annual conference, Granada, Spain, June 16-19 (p. 231 234). Budapest: EDEN Secretariat.

Goodfellow, R. (1999). Expert, Assessor, Co-learner: Conflicting roles and expanding workload for the online teacher. Presentation at CAL99 March 30. Retrieved June 23, 2002 from: http://iet.open.ac.uk/pp/r.goodfellow/CAL99/cal99.html

Groten, H. (1992). The role of study centres at the Fernuniversität. Open Learning 7(1), 50 - 55. 
Kappel, H. H., Lehmann, B., and Loeper, J. (2002). Distance education at conventional universities in Germany. International Review of Research in Open and Distance Learning 2(2). Retrieved June 18, 2002 from: http://www.irrodl.org/content/v2.2/loeper.html

Kleinschmidt, A. (1999). Virtual tutoring in distance education: An approach of centres for distance education for students of the FernUniversität Hagen. The European Association of Distance Teaching Universities (Ed.) ESC 1998 Conference Proceedings, Heerlen, The Netherlands. Retrieved June 18, 2002 from: http://www.unioldenburg.de/zef/literat/esc man.htm

Mesenholl, E. (1998). Untersuchung zur Servicequalität des Fernstudienzentrums in Oldenburg. Manuskript. Oldenburg, Germany: Center for Distance Education, Carl von Ossietzky University of Oldenburg.

Mills, R. (1996). The role of student centres in open and distance education: A glimpse of the future. In Mills R. and A. Tait (Eds.) Supporting the learner in open and distance learning (p. 73-87). London, UK: Pitman Publishing.

Rovai, A. P. (2002). Building Sense of Community at a Distance. International Review of Research in Open and Distance Learning 3(1). Retrieved June 18, 2002 from: http://www.irrodl.org/content/v3.1/rovai.html

Salomon, G. (2000). E-moderating: The key to teaching and learning online. London: Kogan Page.

Tait, A. (2003). Rethinking Learner Support in the Open University UK. In A. Tait and R. Mills, Rethinking Learner Support in Distance Education (p. 185-197) London:

RoutledgeFalmer

Thorpe, M. (2001). Learner Support: A new model for online teaching and learning. In UKOU (Ed.) Student services at the UK Open University (p. 13-22). Papers presented to the 20th World Conferences of the ICDE, Düsseldorf, Germany, April 1-5.

Thorpe, M. (1992). Tuition. In Thorpe M. (Ed.) Evaluating open and distance learning 2 ed. (p. 61-86). Harlow, UK.: Longman.

Wissenschaftsrat. (1992). Empfehlungen zum Fernstudium. Drs. 929/ 92, Nov 13, 1992. Hannover, Germany.

Wissenschaftsrat. (1993). 10 Thesen zur Hochschulpolitik. Drs.1001/ 93. Berlin, Germany.

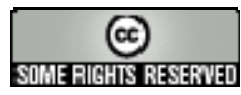

